\title{
SERVICE OVERTIME DAN KAROSHI : KONSEKUENSI DARI ETOS KERJA JEPANG
}

\author{
Arsi Widiandari \\ Program Studi Bahasa dan Sastra Jepang, Universitas Diponegoro, \\ Jl. Prof. Soedarto, SH, Kampus Undip Tembalang, Semarang, Indonesia 50275
}

\begin{abstract}
Abstrak
Meskipun mengalami kekalahan pada Perang Dunia II, Jepang telah berhasil meningkatkan perekonomian negaranya. Hal tersebut tak terlepas dari semangat masyarakat Jepang dalam memulihkan kondisi perekonomian. Setiap perusahaan menanamkan nilai-nilai budaya kepada setiap pekerja, yang tercermin dalam etos kerja Jepang. Nilai-nilai budaya tersebut diantaranya adalah ideologi Metafora keluarga dalam perusahaan, Shushin Koyo Seido, Nenko Joretsu dan Kigyou betsu Kumiai. Pelaksanaan dari nilai-nilai budaya dalam perusahaan Jepang memberikan dampak atau konsekuensi baik dari sisi positive maupun negative. Tak diragukan lagi, hal tersebut memberikan dampak positif seperti yang terlihat dalam perkembangan perekonomian Jepang. Akan tetapi, hal tersebut juga menimbulkan masalah sosial terutama yang dialami oleh para pekerja.Service Overtime dan Karoshi adalah contoh dari konsekuensi yang masih terjadi dalam pelaksanaan etos kerja hingga saat ini. Para pekerja umumnya diharapkan untuk memberikan dedukasi dan loyalitas mereka pada pekerjaan dan perusahaan. Penelitian ini akan mencoba menjelaskan mengenai konsekuensi dari pelaksanaan etos kerja di Jepang.
\end{abstract}

Kata kunci: Service overtime, Karoshi dan Etos kerja Jepang

\begin{abstract}
After defeated on World War II, Japan economy has recover and become one of developed country in Asia. One of the factor that give contribute to Japanese economy rising is Japanese spirit. Company usually teached work culture to every worker that can be seen from Japanese work ethic. For example ideology of Family Methaphore, Shushin Koyo seido (Lifetime employment) Nenko Joretsu ( Salary based on seniority ) and Kigyou betsu Kumiai (Union based on corporation). The work culture practice in Japan company has had positive and negative consequences. As we know, that it has great contributed to Japanese economy development it self. But, it also bring a number of social problem especially to many workers. Service overtime and Karoshi are the example of the consequences of Japan work ethic practice until nowadays. Worker are expected to give their deducation and loyality to job company. This paper will try to give explanation about the consequences of Japan work ethic practice in Japan.
\end{abstract}

Keywords:Service overtime, Karoshi, Japan work ethict

\section{PENDAhuluan}

Keberhasilan perekonomian Jepang pasca PD II seringkali dikaitkan dengan etos kerja Jepang. Salah satu faktor yang dianggap berperan adalah sumber daya manusia Jepang yang masuk dalam industry Jepang.

\footnotetext{
${ }^{*}$ Penulis Korespondensi.

E-mail: arsi901@gmail.com
}

Keberadaan pekerja di Jepang telah lama menjadi sorotan dunia seiring dengan kemajuan perekonomian Jepang pasca PD II. Kemajuan perekonomian tersebut merupakan perpanjangan dari perubahan masyarakat pertanian menjadi masyarakat industri, dimana mayoritas masyarakat Jepang bekerja di bidang industry dan menjadi salaryman. Salaryman berasal dari kata salary yang berarti gaji, dan man yang berarti orang, singkatnya salaryman mempunyai arti yaitu orang yang menerima gaji. 
Pelaksanaan dari nilai-nilai etos kerja Jepang memang tak diragukan lagi memberikan dampak positive terhadap kemajuan perekonomian negara Jepang khususnya pasca kekalahan Jepang di Perang Dunia II. Keberhasilan Jepang dalam meningkatkan perekonomian tak lepas dari semangat untuk maju dan juga manajemen sumber daya manusia di berbagai industri.

Meskipun mendapatkan sorotan dan dianggap sebagai salah satu faktor kebangkitan Jepang pasca PD II, etos kerja Jepang tak lepas dari adanya kontroversi akibat konsekuensi yang harus ditanggung oleh para pekerja. Diantaranya adalah Service Overtime ( sabisu zangyou ), dan Death by overtime ( Karoshi ).

\section{PEMBAHASAN}

\subsection{Etos Kerja Jepang}

Kemajuan ekonomi Jepang yang begitu cepat pasca PD II, seringkali dihubungkan dengan etos kerja Jepang. Etos kerja Jepang seringkali tercermin dalam perilaku pekerja Jepang yang terlihat dari jumlah jam kerja yang panjang, dedikasi pada perusahaan, serta loyalitas pekerja pada perusahaan. Maka tak jarang kita melihat para pekerja umumnya bekerja dengan jumlah jam yang lebih lama dibandingkan dengan pekerja dari negara lain, bahkan seringkali terlihat mereka bekerja di hari libur seperti hari sabtu atau minggu tanpa dihitung lembur.

\subsection{Nilai Budaya pada Perusahaan Jepang}

Etos kerja Jepang tak lepas dari nilai nilai budaya yang ditanamkan oleh perusahaan pada masing-masing pekerja. Meskipun beberapa nilai budaya tersebut telah mengalami pergeseran, namun polanya masih dapat terlihat pada kehidupan masyarakat Jepang. Para pekerja di Jepang seringkali digambarkan sebagai pekerja yang penuh disiplin, berdedikasi tinggi, penuh loyalitas pada pekerjaan dan perusahaan. Maka, berikut ini penulis akan menjabarkan tentang nilai-nilai budaya yang ditanamkan pada perusahaan Jepang. Beberapa nilai budaya yang "khas" yang ditanamkan pada perusahaan Jepang, antara lain adalah:

\subsubsection{Metafora keluarga pada perusahaan Jepang}

Perusahaan Jepang cenderung memasukkan unsur-unsur keluarga dalam filosofi mereka. Seorang pekerja akan dianggap menjadi bagian dari keluarga perusahaan, mulai dari yang bekerja sebagai tukang sapu sampai pemilik perusahaan berada pada satu payung yang sama. Hal ini dapat terlihat dalam perkenalan dimana seseorang cenderung akan menyebutkan dahulu afiliasi mereka daripada posisi mereka dalam pekerjaan.

Adanya unsur keluarga dalam perusahaan Jepang, tak lepas dari konsep "kelompok" dalam masyarakat Jepang. Dalam bukunya yang berjudul Japanese Society, Chie Nakane menyebutkan bahwa masyarakat Jepang adalah masyarakat yang berkelompok dan mempunyai hirarki (tate shakai). Tempat terbaik seseorang adalah ketika ia berada dalam kelompoknya.

Dalam masyarakat, kelompok yang dimaksud bisa berarti keluarga, perusahaan bahkan yang paling besar adalah negara. Bagaimana seseorang menempatkan dirinya dengan tempat yang sesuai dalam masingmasing kelompoknya. masyarakat Jepang mengenal istilah oya-bun dan ko-bun yang menjelaskan status seseorang. Jika dalam keluarga, yang menjadi oya-bun adalah kepala keluarga, maka hal ini juga tercermin dalam perusahaan. Para atasan tidak hanya memberikan evaluasi atas kinerja bawahannya, akan tetapi berperan dalam menjaga hubungan baik, dengan cara mendengarkan pendapat dan aspirasi, dan memberikan motivasi.

Dalam perbincangan antar pekerja, biasanya mereka akan menyebut perusahaan tempat mereka bekerja sebagai "uchi" dan perusahaan saingannya dengan nama " $\sim$ san". Hal ini menunjukkan keterikatan yang kuat antara perusahaan dengan salaryman. 
Metafora ini menuntut loyalitas para pekerjanya. Untuk menanamkan nilai ini, perusahaan umumnya akan memulai kegiatan dengan chourei $=$ apel pagi, yang tidak hanya bertujuan untuk mempersiapkan mengenai apa yang harus dicapai pada hari tersebut, namun juga menanamkan filosofi perusahaan dengan membaca motto dan slogan perusahaan bersama-sama.

Disisi lain, perusahaan wajib memberikan penghargaan dan kemudahan bagi para karyawannya, diantaranya adalah dengan cara pemberian tunjangan anak dan istri, kemudahan mencicil rumah, tunjangan pendidikan anak, sampai pada jaminan hari tua.

\subsubsection{Shushin Koyo Seido dan Nenko Joretsu}

Shushin Koyo Seido dapat diartikan sebagai sistem kerja seumur hidup, yaitu seseorang akan bekerja di suatu perusahaan mulai dari lulus Universitas sampai dengan masa pensiun. Sistem ini booming ketika Jepang mengalami masa kejayaan ekonomi. Dengan tumbuhnya banyak perusahaan besar khususnya manufaktur yang membutuhkan banyak sumber daya manusia handal, perusahaan Jepang sadar bahwa karyawan adalah asset perusahaan yang harus dididik, dilatih sehingga dapat memberikan kontribusi pada perusahaan. Meskipun pada akhirnya sistem ini mengalami pergeseran, pasca resesi ekonomi yang melanda Jepang di tahun 1990, ketika banyak perusahaan yang merubah sistem perekrutan karyawan dari regular ke non-regular, akan tetapi bagi beberapa perusahaan Jepang sistem ini masih dijalankan.

Nenko Joretsu adalah sistem penggajian berdasarkan senioritas. Sistem ini menjamin bahwa gaji seseorang sudah ditetapkan sesuai masa kerjanya dalam perusahaan. Dengan sistem ini, maka perusahaan menjamin harmoni yang tetep terjaga antara pekerja baru dengan pekerja senior.
Hubungan senpai (senior) kohai (junior) begitu kuat dalam perusahaan Jepang, tercermin dari seorang karyawan baru tetaplah seorang kohai bagi rekan kerjanya yang telah lebih dahulu bekerja di perusahaan tersebut. Dalam beberapa kasus, A merupakan senior dari B ketika masih bersama-sama menempuh pendidikan Universitas. B terlebih dahulu bergabung dalam Perusahaan X, setahun kemudian A juga bergabung dalam perusahaan X. Maka, meskipun B jauh lebih junior dari sisi usia dibandingkan dengan $\mathrm{A}$, akan tetapi dalam struktur perusahaan A adalah junior dari B.

Dari sisi perusahaan, sistem ini efektif dalam menanamkan nilai-nilai keluarga dalam perusahaan, serta loyalitas karyawan terhadap perusahaan. Meskipun sistem ini memiliki kelebihan seperti adanya rasa aman dari karyawan akan kenaikan gaji, namun sistem ini juga memiliki kekurangan yaitu dari sisi peningkatan motivasi kinerja karyawan.

Dalam perkembangannya, sistem ini mempunyai sisi negative diantaranya menurunkan motivasi bagi para pekerja untuk dapat meningkatkan levelnya sehingga beberapa perusahaan tidak lagi melaksanaan sistem ini dan mulai menetapkan sistem promosi dan kenaikan gaji berdasarkan kinerja untuk meningkatkan lagi kinerja para karyawan.

\subsubsection{Kigyo betsu kumiai}

Selain metafora keluarga dalam perusahaan, serta lifetime employment, hubungan antara pekerja dan perusahaan juga semakin diperkuat dengan adanya serikat pekerja. Kigyo betsu kumiai adalah serikat pekerja berbasis korporasi menjamin setiap pekerja yang bekerja dalam perusahaan.

Anggota dari serikat pekerja terdiri dari semua lapisan dalam perusahaan mulai dari level manajemen sampai dengan nonmanajemen. Serikat pekerja melindungi dan menyuarakan aspirasi dari para pekerja, bahkan pada beberapa perusahaan besar serikat pekerja seringkali bertindak seperti "pihak manajemen". Serikat pekerja 
Tersedia online di http://ejournal.undip.ac.id/index.php/izumi

bekerjasama dengan pihak manajemen perusahaan perihal peningkatan produktivitas, inovasi teknologi dan restrukturisasi organisasi.

Mayoritas anggota dari serikat pekerja adalah pekerja dari perusahaan besar. Sedangkan pekerja dari perusahaan kecil umumnya tidak tergabung dalam serikat pekerja sehingga tidak dapat menyuarakan pendapat mereka.

\subsection{KONSEKUENSI ETOS KERJA JEPANG}

Setelah kita mengetahui nilai-nilai budaya yang ditanamkan dalam perusahaan Jepang maka selanjutnya kita akan membahas mengenai konsekuensi dari etos kerja Jepang. Disiplin waktu, dedikasi tinggi, dan penuh target adalah cerminan dari pekerja perusahaan Jepang.

Perusahaan sangat menyadari bahwa pekerja adalah asset yang sangat penting untuk meningkatkan dan mengembangkan perusahaan itu sendiri. Tuntutan pekerjaan yang dibebankan pada para pekerja seringkali diiringi dengan tingginya konsekuensi yang harus dibayar oleh pekerja itu sendiri. Hal ini sebenarnya bukan hanya terjadi di Jepang, namun juga di beberapa negara maju lainnya. Maka berikut ini penulis akan mencoba menjelaskan mengenai konsekuensi dari etos kerja yang ditanamkan pada perusahaan Jepang.

\subsubsection{Service Overtime}

Pekerja Jepang dikenal sebagai pekerja keras, hal ini dapat terlihat dari tingginya jumlah jam kerja pekerja Jepang jika dibandingkan dengan negara-negara lain. Perusahaan tidak menganggap hal tersebut sebagai overtime, tetapi dinilai sebagai bentuk komitmen akan loyalitas karyawan terhadap perusahaan. Dengan demikian pekerja tidak mendapatkan penghargaan lebih atas jam kerja yang melebihi standar yang ada.
Grafik 1. Perbandingan jumlah jam kerja Jepang dan negara-negara lain ( 2000-2007)

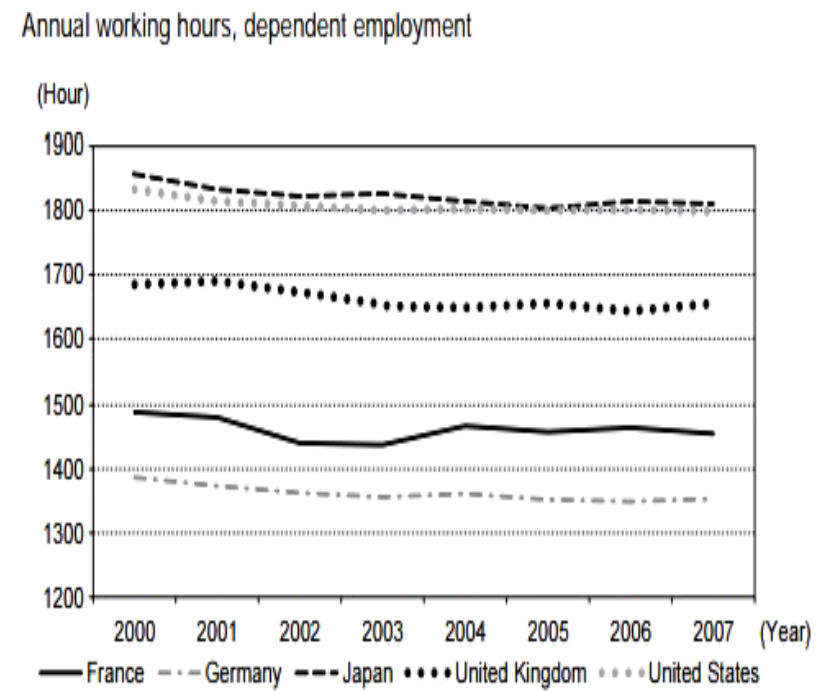

Source: OECD, 2008, hitp.//stats.oecd.org/WBOS/ndex.aspx.

Pada grafik diatas merupakan perbandingan jumlah jam kerja antara Jepang dan beberapa negara lain kurun waktu tahun 2000 sampai dengan 2007. Pada grafik tersebut, dapat terlihat bahwa jumlah jam kerja di Jepang lebih tinggi jika dibandingkan dengan negara lain. Meskipun jumlah jam kerja tersebut cenderung mengalami penurunan, akan tetapi jumlahnya masih lebih tinggi jika dibandingkan dengan negara lain.

Undang-Undang Standar Tenaga Kerja yang diamandemenkan pada tahun 1993 menetapkan bahwa jumlah jam kerja di Jepang adalah 40 jam / minggu atau 8 jam / hari. Dalam kenyataannya, mereka seringkali bekerja melebihi jam kerja yang telah ditetapkan dalam Undang-undang, bahkan seringkali pulang larut malam, atau masuk pada hari sabtu dan minggu tanpa dihitung lembur.

Tingginya tuntutan dari perusahaan agar mereka dapat bekerja sesuai dengan target, menimbulkan fenomena yang kemudian dikenal dengan Service Overtime atau Sa-bisu Zangyou. Pada sebuah survey yang dilakukan oleh Japan Institue Labor di tahun 2002, golongan usia yang paling banyak melakukan Service Overtime adalah 
mereka yang masih tergolong usia produktif dari 24 sampai dengan 34 tahun. Lalu pada usia 34 tahun ke atas cenderung mengalami penurunan.

Grafik 2. Persentase Service Overtime berdasarkan usia pekerja

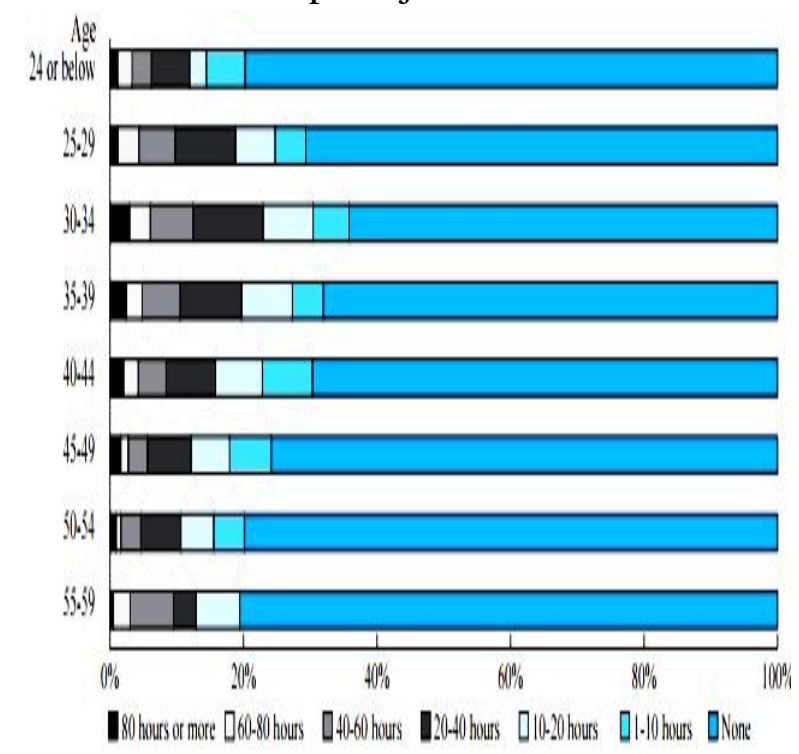

Dalam wawancara yang dilakukan oleh Yomiuri Shinbun kepada sejumlah pekerja yang melakukan Service Overtime, mengatakan bahwa alasan mereka menjalani Service Overtime adalah karena tuntutan dari perusahaan yang begitu tinggi, sehingga tidak dapat menyelesaikan target pada saat jam kantor telah berakhir pada hari tersebut. Profersor Ogura dari Waseda University mengutarakan pendapatnya bahwa hal tersebut bukan berarti menunjukkan bahwa pekerja Jepang tidak bekerja secara efisien, namun seringkali pekerja tidak dapat menyelesaikan pekerjaannya karena harus menghadiri meeting perusahaan. Dalam lingkungan bisnis Jepang, meeting tidak hanya berarti untuk membuat keputusan, namun juga sebagai sarana bertukar informasi yang akan membantu dalam membuat keputusan.

Overtime umumnya diajukan kepada atasan, namun seringkali bawahan tidak mengajukan overtime kepada atasan mereka. Supervisor dan manager baru mengetahuinya setelah bawahan telah melakukan overtime.
Seorang pekerja haruslah bertanggungjawab atas pekerjaannya, sehingga seringkali melakukan service overtime bahkan membawa pekerjaannya ke rumah.

\subsubsection{Karoshi}

Konsekuensi lain dari etos kerja Jepang yang harus dihadapi oleh pekerja Jepang adalah Karoshi. Dalam bahasa Jepang, Karoshi〔過労死〕 Berasal dari kanji 過 yang berarti berlebihan, kanji 労 yang memiliki arti bekerja dan kanji 死 ang berarti meninggal atau mati. Dengan demikian, dapat diartikan bahwa Karoshi adalah fenomena dimana kematian seseorang yang diakibatkan oleh kelelahan akibat kerja berlebihan.

Istilah ini muncul pada tahun 1970an, dan tercatat pada tahun 1978 terdapat 17 kasus karoshi. Media massa mengkategorikan istilah ini untuk menjelaskan kondisi seseorang yang meninggal tiba-tiba akibat terlalu lelah bekerja. Penyebab utama dari karoshi umumnya adalah serangan jantung, stroke, yang diakibatkan dari terlalu lelah dan lama bekerja. Dengan kondisi perekonomian yang akhir-akhir ini mengalami penurunan, masyarakat Jepang menganggap bahwa untuk memulihkan perekonomian kembali, maka mereka harus bekerja lebih giat lagi. Dengan demikian fenomena karoshi ini menjadi suatu permasalahan sosial yang terjadi di masyarakat Jepang khususnya di antara para pekerja Jepang.

Awalnya karoshi banyak terjadi pada mereka yang bekerja di sektor non managerial seperti supir truk, buruh dari pedesaan. Namun, akhir-akhir ini kasus karoshi banyak juga ditemukan pada jenis pekerjaan managerial. 
Tabel. 1. Jumlah kasus Karoshi terkait jenis pekerjaan

\begin{tabular}{|l|l|l|l|l|l|}
\hline & $\begin{array}{l}199 \\
7\end{array}$ & $\begin{array}{l}199 \\
8\end{array}$ & $\begin{array}{l}199 \\
9\end{array}$ & $\begin{array}{l}200 \\
0\end{array}$ & $\begin{array}{l}200 \\
1\end{array}$ \\
\hline Specialist & 10 & 10 & 12 & 15 & 25 \\
\hline $\begin{array}{l}\text { Manageria } \\
1\end{array}$ & 27 & 26 & 20 & 20 & 26 \\
\hline Clerical & 14 & 21 & 15 & 16 & 18 \\
\hline Sales & 1 & 3 & 5 & 3 & 5 \\
\hline Service & 0 & 3 & 2 & 3 & 6 \\
\hline Driver & 9 & 7 & 12 & 12 & 30 \\
\hline Engineer & 10 & 18 & 8 & 6 & 20 \\
\hline Other & 2 & 2 & 7 & 10 & 13 \\
\hline Total & $\mathbf{7 3}$ & $\mathbf{9 8}$ & $\mathbf{8 1}$ & $\mathbf{8 5}$ & $\mathbf{1 4 3}$ \\
\hline
\end{tabular}

Sumber: Ministry of Health, Labour and Welfare

Secara hukum, karoshi sama seperti kecelakaan pekerjaan, dan bisa diajukan kepada pihak asuransi, tapi kenyataannya sulit membuktikan suatu kematian sebagai karoshi. Hal tersebut dapat terlihat dari persentase jumlah kasus kematian yang masuk dalam kategori Karoshi, yakni 1.498 kasus yang diajukan, hanya 244 kasus yang dianggap karoshi.

Dalam Enforcement Regulations of the Labour Standar Law, dijelaskan jenisjenis kasus yang dapat dikategorikan sebagai karoshi.

1. Mr A bekerja di sebuah perusahaan pengolahan makanan dengan jam kerja 110 jam per minggu, dan meninggal akibat serangan jantung pada usia 34 tahun. Jenis kematian pada kasus ini termasuk dalam kategori Karoshi.

2. Mr B seorang pengemudi bis, bekerja dengan jam kerja 3000 jam per tahun. Tidak memiliki satu pun hari libur dalam 15 tahun terakhir sebelum akhirnya meninggal karena penyakit stroke pada usia 37 tahun.

3. $\mathrm{Mr} \mathrm{C}$ bekerja pada sebuah perusahaan percetakan besar di Tokyo. Sebelum meninggal akibat penyakit stroke pada usia 58 tahun, memiliki catatan jam kerja sebanyak 4320 jam per tahun.

4. Ms D, seorang perawat berusia 22 tahun meninggal akibat serangan jantung setelah bekerja selama 34 jam berturut-turut dalam lima bulan terakhir.

Apabila kita melihat contoh kasus untuk pengkategorian karoshi, maka dapat terlihat bahwa jumlah jam kerja adalah salah satu yang menjadi bahan pertimbangan apakah kematian seseorang dapat dikategorikan dalam Karoshi atau tidak.

Kasus karoshi pertama adalah pada tahun 1969 yang menimpa seorang pekerja di perusahaan surat kabar di bagian pengiriman, meninggal akibat penyakit stroke. Media massa mulai mengangkat fenomena ini pada tahun 1980 setelah seorang pekerja yang bekerja di bagian top manajemen meninggal dunia tanpa adanya gejala penyakit.

Berdasarkan MHLW, pada tahun 2002 jumlah kematian yang disebabkan oleh jam kerja yang panjang sejumlah 317 laporan, dan mengalami peningkatan jika dibandingkan dengan tahun sebelumnya yaitu hanya mencapai angka 143 kasus.

Selain karoshi yakni kematian yang disebabkan oleh kelelahan akibat terlalu lama bekerja, adapula jenis kematian yang disebabkan oleh tekanan pekerjaan sehingga menimbulkan tindakan untuk mengakhiri hidupnya dari pekerja itu sendiri, yang kemudian dikenal dengan istilah Karojisatsu.

Seperti halnya karoshi, karojisatsu juga menjadi permasalahan yang terjadi dalam masyarakat Jepang. Tuntutan pekerjaan yang tinggi, seringkali menimbulkan kondisi dimana para pekerja mengalami stress. Dalam bisnis Jepang, pencapaian seorang pekerja dilihat dari tercapainya target pekerjaan. Dengan demikian, jika seseorang tidak mencapai target dalam pekerjaannya, maka akan dianggap tidak focus dalam bekerja.

Beberapa faktor yang dapat menimbulkan stress yang berakibat bunuh diri diantara lain

a. Jumlah jam kerja yang panjang, seringkali seorang pekerja harus pulang larut malam atau masuk di hari sabtu dan minggu. Ketika Jepang mengalami krisis ekonomi, dan merubah sistem perekrutan karyawan, hal tersebut bukan berarti menunjukkan bahwa bisnis perusahaan menurun. 
Perusahaan seringkali membebankan pekerjaan kepada karyawan. Dengan kata lain, beban pekerjaan yang harus ditanggung oleh seorang pekerja akan meningkat jika dibandingkan dengan beban pekerjaan sebelumnya.

b. Perusahaan Jepang seringkali memberikan bebean pekerjaan yang tinggi pada para pekerjanya. Bahkan pasca resesi ekonomi yang melanda Jepang di tahun 1990-an, perusahaan meningkatkan ekspektasi dan mengharapkan agar karyawannya dapat bekerja lebih giat lagi.

c. Konflik internal antar karyawan yang seringkali menimbulkan bullying. Adapula konflik internal antar karyawan, sehingga salah seorang secara tiba-tiba diminta untuk mengundurkan diri.

d. Tekanan yang berlebihan bagi para pekerja yang bekerja di posisi tengahtengah antara karyawan dengan perusahaan ( top managemen ). Bagi mereka yang berada di posisi pekerjaan seperti ini akan mendapatkan tekanan dari kedua belah pihak, yaitu karyawan dan perusahaan ( top managemen ).

Berdasarkan laporan dari Health, Labor and Welfare Ministry, pada tahun 2013 sebanyak 1409 orang mendaftarkan diri mereka untuk mengajukan kompensasi atas penderitaan yang diakibatkan oleh depresi di tempat bekerja sebagai akibat dari tingginya jam kerja. Jumlah tersebut meningkat 152 kasus jika dibandingkan dengan tahun sebelumnya, namun hanya 436 yang mendapatkan kompensasi.

Faktor-faktor yang melatarbelakangi tingginya jumlah orang yang mengajukan kompensasi atas kerusakan mental dan kematian yang diakibatkan dari tingginya jumlah jam kerja, diantaranya adalah tekanan dalam bekerja, pelecehan seksual, dan bullying di tempat bekerja.

Meskipun jumlah keluarga yang mengajukan kompensasi atas kematian yang disebabkan oleh terlalu banyak bekerja begitu tinggi, namun jumlah kasus yang dianggap sebagai Karoshi jumlahnya tidaklah banyak. Hal tersebut mengingat bahwa yang dikategorikan sebagai Karoshi umumnya akan memperhatikan elemen jam kerja seseorang sebelum meninggal, tempat kejadian ketika seseorang tersebut dinyatakan meninggal, dan waktu kejadian apakah pekerja tersebut meninggal persis setelah bekerja atau tidak.

\section{SIMPULAN}

Tingginya etos kerja Jepang yang ditanamkan pada pekerja tercermin dalam perilaku pekerja itu sendiri. Diantaranya adalah tingginya jumlah jam kerja jika dibandingkan dengan negara lainnya, disiplin waktu bekerja, dedikasi pada perusahaan, dan loyalitas dalam bekerja.

Dalam mendidik dan membentuk pekerja, perusahaan umumnya akan menanamkan nilai budaya serta doktrin akan nilai-nilai perusahaan kepada para pekerja. Diantaranya adalah dengan memasukkan unsur keluarga pada perusahaan, sehingga para pekerja menyadari bahwa perusahaan adalah keluarga itu sendiri. Bagaimana mereka harus bekerja penuh dedikasi adalah untuk meningkatkan perusahaan itu sendiri.

Akan tetapi, bentuk loyalitas dari para pekerja juga diiringi oleh konsekuensi dari yang harus diterima oleh pekerja, diantaranya adalah Service Overtime dan Karoshi. Jumlah jam kerja yang begitu panjang melebihi standar yang telah ditetapkan seringkali merupakan bentuk loyalitas dan tanggungjawab pekerja terhadap perusahaan.

Fenomena ini menjadi permasalahan yang harus dihadapi oleh masyarakat Jepang dan juga tantangan bagi perusahaan Jepang dalam mengelola sumber daya manusianya. Metafora keluarga seringkali dijadikan dasar untuk meningkatkan loyalitas dan kinerja pekerja terhadap perusahaan. Budaya korporasi yang tercermin dalam etos kerja Jepang, dilaksanakan semata-mata demi meningkatkan keuntungan perusahaan tanpa memperhatikan konsekuensi yang harus dihadapi oleh pekerja itu sendiri. 


\section{DAFTAR PUSTAKA}

. 1986. Salaryman in Japan. Japan: Japan Travel Bureau, Inc

Nakane, Chie. 1970. Japanese Society. London : Weidenfield \& Nicolson

Sugimoto, Yoshio. An Introduction to Japanese Society. Cambridgr University Press. 2003

http://www.amrc.org.hk/content/karoshi-andkarojisatsu-japan) www.eurofound.europe.eu

www.ilo.org/safework/info/publications/wcm s_211571/lang-en/index.htm

www.jil.go.jp/archives/bulletin/documents/2 00302.pdf )

www.yomiuri.co.jp/adv.wol/dy/option/societ y_120206.html

http://www.jil.go.jp/english/reports/documen ts/jilpt-reports/no.7.pdf 